\title{
"....So from then, we a bit freaky at home, we were scared": Challenges of Providing Foster Care to a Child Living with HIV in South Africa
}

\author{
Jenni-Kate Warwick, Johannes John-Langba* \\ Department of Social Development, University of Cape Town, South Africa
}

\begin{abstract}
Foster care is currently the main form of care available to HIV positive children in South Africa, who are no longer in the care of their parents. Thus, the importance of understanding the challenges and needs of foster carers could not be over-emphasized. This paper reports on a study that explored the experiences and needs of foster carers of HIV positive children in the Western Cape Province of South Africa. Participants were recruited from two organizations that provide services to HIV positive children and their foster carers in Cape Town. Grounded on family stress theory and systems theory, in-depth interviews were conducted with 18 foster carers of HIV positive children including 16 female carers and two male carers. Results indicated that the challenges facing foster carers are multifaceted and include the initial adjustment period, interactions with biological parents, finances, dual diagnoses, stigma and fear, the foster carers' own mental and physical health, management of the child's medication and dealing with the child's emotional pain. Health care services were found to be easily accessible, but social services and educational support proved to be a challenge to foster carers. This paper highlights the need for additional emotional support for foster carers and the importance of providing opportunities to voice their challenges and if needed, receive appropriate training and support.
\end{abstract}

Keywords Foster Care, Foster Carers, HIV Positive Children, South Africa

\section{Introduction}

Prior to the introduction of anti-retroviral medication in South Africa, adults and children were becoming ill quickly and many HIV positive mothers could not manage or afford to look after their sick children. Grandparents were overwhelmed with taking care of both their sick children and sick grandchildren (Kiggundu \& Oldewage-Theron, 2009; Townsend \& Dawes, 2004). This, along with the increasing death rate of adults with AIDS, led to the establishment of many residential facilities for such children, where appropriate care could be provided (Hearle \& Ruwanpura, 2005) Since the introduction of anti-retroviral medication, many children who had previously been very sick, now have the opportunity to live longer, healthier lives. This change meant that the move to residential care needed to be re-evaluated as children were no longer in need of just day-to-day care, but they needed to be raised with the future in mind. While in residential care, the children were guaranteed good nutrition and strict adherence to their drug regimes, but they were missing out on family life (Townsend \& Dawes, 2004), hence the move to consider foster care as an alternative form of care for these children. In the context of South Africa, foster care is when a child in need of care and protection is legally placed (by order of the Children's Court) in the care and safety of an adult person other than the biological parents. This adult may be a family member or unrelated to the child (Department of Social Development, 2007).

Foster care has been implemented for many years, without formal laws and policies to govern its practice. Formal laws to regulate foster care were only drawn up in the last century (Rymph, 2012). The practice of foster care is viewed with a fair amount of diversity across the world. In America, foster care is seen as a short term intervention, lasting up to 22 months, during which time preparations must be made for the child to return to their home or to another form of long term care (Maluccio, 2003). In the Netherlands however, foster care is seen as both a short term and long term intervention, depending on the circumstances of the child and family (Strijker, Knorth \& Knot-Dickscheit, 2008). As a short-term intervention, it has the aim of treating a child or parent with the view of returning the child to their birth family (Strijker, et al., 2008). The second approach is to provide long term foster care until the child is 18 , with the 
aim of providing continuity of care and respect for the child's right to a stable rearing situation. (Strijker, et al., 2008).

The South African model of foster care is comparable to the model used in the Netherlands, as it makes allowances for both short and long term forms of official foster care placements. In South Africa, official placements refer to foster care arrangements that are as a result of a foster care order from the Department of Social Development, whereas an unofficial placement is often the result of an agreement between family members, in which social services has not been involved. Unofficial foster care placements have been a recognized form of alternative care for many years in South Africa, predominantly in the form of kinship care (Thomas \& Mabusela, 1991). Since the move to deinstitutionalize the care of HIV positive children, foster care, on both a formal and informal basis has become one of the preferred methods of providing care for these children (Townsend \& Dawes, 2004). While appearing to have good potential as an effective means of providing care for HIV positive children, foster care comes with many challenges. Murray, Tarren-Sweeney, and France (2010) suggest that the combination of a high burden of care and perceived disempowerment, together with dysfunctional relationships with social services contributes heavily to a lack of sustainability in foster placements. They also suggest that some of the main challenges of foster care include unhelpful interaction with the children's agency social workers, difficulty in accessing specialist services, contact with the child's birth parents, lack of respite care, training and support (Murray, et al., 2010).

According to Thomas and Mabusela (1991) the challenges of foster care are numerous, including issues pertaining to loyalty and identity, problems with discrimination between foster children and biological children of foster carers, redefinition of the family, change of the family structure of the foster family and the resultant strain of the transition, feelings of loss on the part of the child and the biological family, and the need for the biological and foster families to work together. The challenges related to children's needs include sexual abuse of children, disciplining children, children's emotional needs, children's bereavement, and the children's physical health (Kuo \& Operario, 2010). Lastly, the challenges related to physical and mental health included carer bereavement, disappointment with unmet expectations regarding life course, tiredness and stress due to caring for children, stigma, carer's sense of isolation, stress of combining families and the carer's physical health (Kuo \& Operario, 2010).

In a study by Kiggundu and Oldewage-Theron (2009) many of the guardians were found to struggle with high blood pressure, diabetes, arthritis and depression and some were also HIV positive.

Extended family foster placements in South Africa present additional challenges to those presented in non-kinship placements. In particular, grandmothers providing care for their orphaned grandchildren faced not only the loss of their children, but also the loss of the support that their children would have given them in their old age.). Old age and sickness were also challenges that, although not specific to family members, were often experienced by grandmothers providing foster care (Kiggundu \& Oldewage-Theron, 2009). Rajcoomar's (2005) study of the impact of HIV/AIDS on rural gogos (grandmothers) found that the main stressors of grandmothers providing care for their orphaned grandchildren were the financial costs of funerals and of raising the orphaned children, caring for sick children and adults, a lack of family support and grief counseling, and insufficient knowledge of HIV/AIDS and how to protect themselves from infection. There is also evidence that grandmothers providing care for their orphaned grandchildren have the additional stress of needing to plan for the real possibility that they too might pass away while their grandchildren are in their care (Nyasani, Sterberg, \& Smith, 2010; Kiggundu \& Oldewage-Theron, 2009). Boyer and Poindexter (2005) identified five barriers to permanency planning for older foster carers of HIV affected and infected children. These barriers include lack of knowledge about the legal process, lack of legal authority, emotional concerns, lack of informal social support and HIV-related stigma (Boyer \& Poindexter, 2005).

Although a fair amount of research on the challenges of providing foster care for AIDS orphans has been carried out in the rural areas of South Africa (Jones, Sherman, \& Varga, 2005; Kiggundu \& Oldewage-Theron, 2009; Kuo \& Operario, 2010; Ogunmefun, Gilbert, \& Schatz, 2011; Rajcoomar, 2005), there is however a dearth in research in the context of urban and peri-urban setting in South Africa, and in the Western Cape in particular. There is also an apparent gap in research specific to the foster care of children who are HIV positive regardless of their orphan status. This paper seeks to answer the question: what are the experiences and support needs of fostering a child living with HIV in South Africa? It is premised on the assumption that foster carers of HIV positive children in South Africa experience numerous challenges in their efforts to provide care for their HIV positive foster children and as a result, have specific support needs. The stress linked to foster care is played out and experienced in the family in which the foster child is placed. Systems theory also plays a key role in understanding the impact of stress on the foster family. Grounded on Family Stress Theory (McCubbin, 1993) and Systems Theory (Greene \& Ephross, 1991), this paper therefore explores the challenges of fostering HIV positive children in the context of post-apartheid South Africa. Family Stress Theory is a developmental theory that explores why some family systems adapt and even grow and thrive when faced with situational stressors or transitional events, while other family units deteriorate and disintegrate under similar circumstances (McCubbin, 1993). The stress linked to foster care is played out and experienced in the family in which the foster child is placed. The basic assumption of Systems Theory is that the whole is greater than the sum of its parts 
(Greene \& Ephross, 1991). Systems Theory also plays a key role in understanding the impact of stress on the foster family, as it views the family as an interconnected system. Systems Theory emphasizes interdependence and interaction between the components of a system and has an interest in what makes social systems, in this instance, families, maladaptive or adaptive, making it useful for understanding family dynamics (Greene \& Ephross, 1991).

\section{Methodology}

The study was carried out using a qualitative research design that took the form of an exploratory study, as more information is needed in the area of foster care for HIV positive children, particularly in an urban and peri-urban setting in South Africa. A semi-structured interview schedule was used to guide in-depth, face-to-face interviews that were held with foster carers in order to elicit their perceptions of their experiences and needs in caring for their HIV positive foster child.

Foster carers of HIV positive children are the population that this study sought to investigate. In order to obtain a broad socio-demographic mix of participants from two organizations that provide services to HIV/AIDS children were purposively selected from which 18 foster carers of HIV positive children were recruited. Due to the broad client base of one of the organizations from where participants were recruited, a fairly diverse population was found in terms of geographical location, population group and socio economic status. The participants were purposively selected based on specific inclusion criteria of being a foster carer of a HIV positive child and should have been providing care for the same child for a period of at least two years in order to attempt to differentiate between initial adjustment challenges related to new foster placements and long term challenges that foster carers experience.

Participants were recruited from two community-based organizations in Cape Town that provide health and social services to children living with HIV/AIDS and their families. One of the organizations supports anti-retroviral therapy for more than 1400 children and 400 caregivers at five sites in Cape Town and the other is a long term residential care facility that focuses on family reunification and integration of children into foster families, while still providing short term residential care for children awaiting reunification or placement in foster families.

Of the 18 participants that were interviewed, 16 were female, and two were male. Four of the participants were White, two were Indian, four were Coloured and eight were Black. Their socio-economic status varied significantly, from accountants to unemployed grandmothers, living off their state pensions and the foster care grant. The majority of the participants (eight) were Black, four were Coloured, two were Indian and four were White. The foster children ranged in age from 7 to 16 and the participants ranged in age from 21 to 68 years. All the participants resided in the greater Cape Town area including the townships (lower socio-economic areas of the city, resident to the "previously disadvantaged 'population groups)

In-depth interviews (IDI) were conducted with the foster carers, to obtain information about their experiences and needs. The interviews were conducted in the preferred languages of the participants, making use of an additional trained field worker in one instance when there was a language barrier. The additional field worker was knowledgeable about the aims and objectives of the research, as well as about the ethical considerations that they needed to bear in mind while conducting the interview. The interviews, with the permission of the participants, were audio-recorded making use of an electronic recording device.

The in-depth interviews were conducted using a semi-structured interview schedule as a tool to guide the conversation. The interview schedule explored information about the challenges and rewards of providing foster care, the support that foster carers receive and the support that they wish they could receive, their perceptions of their role in their foster child's life and about their access to and utilization of medical, educational and social services pertaining to their child. There were 14 official placements and three unofficial placements represented in the interviews. Official placements refer to placements that are as a result of a foster care order from the Department of Social Development, whereas an unofficial placement is often the result of an agreement between family members, in which social services has not been involved. Of the three unofficial placements included in this study, one was unofficial due to the child being a foreign national; one was unofficial due to the foster carers being foreign nationals, and one as a result of an informal arrangement. Six of the placements were kinship placements, five were placements in which the foster parent and child were of the same ethnicity but with no family ties and six of the placements were across population groups. Two of the foster carers were fostering children who were not only HIV positive but also had special needs. A total of 14 IDIs were conducted with the primary caregiver of the foster child, with one of these interviews being attended by both foster carers, who were in this case, same-sex partners. Three of the interviews were held with foster family members other than the primary caregiver due to the primary caregiver being either too old and frail to attend the interview, battling arthritis, or unavailable.

This study employed an adaptation of Creswell's approach to data analysis (1998 in De Vos, Strydom, Fouche \& Delport, 2005) that involved collecting and recording data; managing the data; reading and writing memos; describing, classifying and interpreting the data and then representing and visualizing the findings (De Vos et al., 2005). The qualitative data was verified for trustworthiness by assessing credibility, transferability, dependability and confirmability 
(Lincoln \& Guba, as cited in Babbie \& Mouton, 2007). Of note, all names of persons, places and other identifiers have been replaced with a _ [dash] in reporting the findings of this study. Ethical approval to conduct the study was granted by the Department of Social Development and the Faculty of Health Sciences (University of Cape Town, South Africa). Ethical clearance was also obtained from the two organizations where the participants were recruited.

\section{Limitations of the Study}

By conducting the interviews at organizations where the participants receive services, the participants could have felt the need to give what they deemed to be socially desirable answers. To mitigate this, participants were assured during the written informed consent process of their privacy, confidentiality and anonymity and that their participation in the study was voluntary. They were also assured that their participation or non-participation would not jeopardize their existing relationship with the service provider. Three of the interviews were conducted with an extended family member, which could have impacted on the accuracy of the responses obtained. The participants were however debriefed directly after every interview. This provided another opportunity for the participants to reflect on the accuracy of their responses Lastly; the study did not take into account the perspectives of the HIV positive foster children. A follow up study involving HIV positive foster children was recommended.

\section{Findings}

It is apparent from this study that the challenges facing foster carers of HIV positive children are extensive and can be overwhelming at times. A range of challenges emerged with the main challenges including: the initial adjustment period, dealing with the child's HIV positive status, interactions with biological parents, finances, dual diagnoses, stigma and fear, the foster carers' own mental and physical health, managing the child's medication, and dealing with the child's emotional pain.

\section{The Initial Adjustment Period}

The majority of the participants reported really struggling to understand their foster child in the initial period of adjustment after the child moved in with their family. This was true for the children that came from residential facilities, and those who had just suffered the loss of their primary care giver.

This was evidenced in a number of the statements made by the foster carers.

Uh, there were things that we couldn't understand about her. Because sometimes she would become cross and we wouldn't know the reason. - 26 year old foster mother

\section{Another foster carer reported that:}

Sometimes he would get so frustrated if he don't get what he wants...because there in the home... you play with everybody's toys, everybody's got one care giver you see, so um, I couldn't touch him or walk past him and touch him, then he will just hit you. But he's out of that now. That was one of the problems that I had. -58 year old foster mother

\section{Dealing with Child's HIV Positive Status}

A number of the participants alluded to their initial heartache, fear and uncertainty when learning about their foster child's status, particularly those in situations where the child was only diagnosed after already living in their care. For many this meant dealing with their own heartache, fears and concerns for the future, while remaining strong for their foster child.

A 32-year-old unofficial foster mother spoke about her fear as follows:

I used to be scared! Because they say that if you touch the blood of someone who is positive, you will also be positive. So I tell myself, I must do this, because he must be well. Because he was really sick.

Another participant shared about her emotional response to the news of her foster child's status:

I did cry for 2 days. For 2 days I couldn't eat, I couldn't drink. But I still say thank you Lord for helping me, and I'm still standing and I'm prepared to climb the mountain with my son, for better or for worse, I'll climb it, because he didn't ask for this. - 43-year-old foster mother

A 21-year-old extended foster family member who lives in the same house as the foster child shared the family's reaction to the news of their foster child's status:

So from then, we a bit freaky at home, we were scared, but as we learnt, we never criticized her, because we know it's a living thing. And my mother is also HIV positive, and her sister is also positive, and her older uncle is also positive, so we never have that criticism, because we know people in the same position...now we have to focus on how she is living now.

Some of these foster carers also had the difficult task of explaining to their child that they are HIV positive. For example, a 43-year-old foster mother shared the following:

Uuum. He was a little bit off. He didn't even question me. He didn't question my husband. He didn't question anyone... I say 'um, I have to speak to you now. We are going to work with an illness, it can be deadly, but it can also help you. It's between me and you and Allah. We have to help each other now. I'm going to help you, you have to help me. We gonna talk openly. We don't hide 
things. If you need anything, come to me. Talk about sex, you come to me...Because I stand as a mother, as a father, as your counselor. We talk openly with each other.

It seemed that despite the fear and uncertainty that many foster carers experienced as a result of their foster child's HIV status, the revelation of their child's status often resulted in a renewed sense of purpose in their care of their foster child.

\section{Interactions with Biological Parents}

The foster carers who are not related to their foster children and who had interactions with the biological parents of their foster children reported those experiences to be fairly trying and often even traumatic.

In an interview where two foster fathers in a same sex marriage were interviewed, they reported on their experiences with their foster daughter's biological mother as follows:

The woman in the ID book was a very beautiful black woman and the woman sitting in front of me was a woman that had had a very hard time...I cried, I held her and I cried-Foster father.

$\mathrm{He}$ cried for days. And then T cries because then why is daddy crying. You know, it's addictive. And then cried because they are both crying. It's still a very painful thought-Foster father

Another foster carer spoke about the drama that she had to endure as a result of interaction with the biological mother of her foster children:

... The mother knew where I stayed. When she brought

$\mathrm{L}$ to me, I gave her my address and my telephone number so that she can't say I kidnapped her child. And then she just pitched up anytime she wanted and she never came by being sober, she always came here when she was drunk, so for me the most difficult part was the involvement of their mother. That was it. But now, I always say, I'm not glad that she's not there anymore, but it makes things much easier. - 58-year-old foster mother

Another foster carer spoke about her attempt to connect with her child's biological mother, but to no avail:

She was very rude and didn't want us to take her child... So I said to her, 'I don't want to take your child, but tells me that there are no other options. If you feel you want to keep him, it's not a problem; it's not that I have no children or something. We will bring him to see you, and you are more than welcome to come into my home to see him. So anyway, she ignored us, so she has always just been very rude. -48 -year-old foster mother
It is clear from the above quotes that establishing or maintaining contact with biological parents presents its own set of challenges, which can seem overwhelming for foster carers, in addition to the heavy load that they already carry.

\section{Financial Challenges}

For the participants who came from the townships (11 out of the 18 participants), the issue of finances emerged as the primary challenge. While most were in receipt of the foster care grant, they did not feel that it was sufficient to cover all the expenses associated with raising an HIV positive child. A common complaint was the rising cost of healthy food and a genuine concern was shown by most of these foster carers that they struggle to provide their foster children with the healthy food that they know the children need, especially in light of their status.

This was evidenced through the following two quotes:

The most difficult part is when you don't have enough money. Because especially if you've got a sick child at home, you must make sure there's some veggies, there's food...you see, especially because I don't want her to be hurt. Because I'm always scared that if she can get hurt, she might be sick again...If I buy a pair of shoes, I have to buy another one. 'Mommy where is mine? Where is mine?'... So if I'm going to buy something, I have to make the budget right so that, you see, they are the similar age and I buy one for the bigger girls, I must buy 2 pairs of them. If I buy for the little ones, I must make sure that I'm going to have something for the other one... When I'm looking I'm not only looking for today. I'm also looking for their future. Because I want my kids to be educated but I don't have the funds. - 39-year-old foster mother

I buy something nice for her because you know she must eat...she must eat to get healthy. So sometimes the money get finish. Sometimes there isn't enough to get something to eat. -56 -year-old foster mother

In many incidents, particularly with the older foster carers, they were often financially supporting not only their foster child, but also other members of the family who are unemployed. In 3 of the families, the foster child and the foster carer, who received a state pension or another grant, were seen as the bread winners in the family, due to the government grants that they receive and the widespread unemployment in their extended families.

This was evidenced through the following interaction with a 52-year-old unofficial foster mother:

Ja. It's the only grant money you see. You have to pay transport, pay the school fees, buy this, and buy that.

Lack of finances can also make it difficult for the foster carers to get the children to the necessary medical 
appointments, as evidenced by the following quote:

Sometimes when I come here, when his date fall on the 22 nd or 25 or so, up to 27 and 28, that time I haven't got money. There was two times I wasn't here but I phone in and I ask them can I come next week. Then it's the end of the month and I have money. - 52-year-old foster mother

The foster carers whose foster children receive their medical care through a government tertiary hospital are able to claim transport money back from the Hospital Benevolent Fund, which many found to be of great assistance, provided they had enough money to make it to the appointment in the first place. It is clear that financial support is a big need for many foster carers of HIV positive children.

\section{The Dual Diagnosis Challenge}

Dual diagnoses refer to the presence of multiple diagnoses in the same child. Two of the foster carers interviewed had foster children for whom their HIV status was perceived by the foster carers to be secondary to other diagnoses, including Foetal Alcohol Syndrome (FAS), autism and cerebral palsy (CP). Social and emotional support seemed to be a prominent need for the foster parents dealing with dual diagnoses. For these foster carers, the other diagnoses were far more stressful and time consuming to manage than the $\mathrm{HIV}$, as evidenced through the following quote:

$\mathrm{HIV}$ is the easiest thing to manage in my opinion. If you understand how to administer the dosages and you're strict about adhering to the regiments, its 2 minutes a day you know. - 51-year-old foster mother

However, both foster carers felt HIV was the diagnosis that hindered their ability to access the specialized services that their children require, as explained in this quote:

I think his status could at certain places also stand against him. They don't say it, but it is obvious. Dr is in charge of my area and I have been trying him from the time was 3 and the doctor sent his report through and I phoned him and asked him and he said 'oh I see the child has AIDS, I would suggest__. And we had one row, a big argument. - 48-year-old foster mother

These parents also reported feeling very isolated in their role of parenting their children as evidenced through the following quote:

And the parents, what I've noticed is, if their child has cerebral palsy (CP), they only want to deal with other parents with CP. If the child is Downs, then the facilities available are all specific to Down's Syndrome. Deaf and dumb... blind school...each one has their clique. And then you get a childlike thrown in the mix. I mean I phoned the CP organization. The lady is very nice but she told me I needed to get hold of parents of
HIV positive children, because he is not fully CP. And then he's not fully autistic. So that is the challenge. Where does he click? - 48-year-old foster mother

\section{Stigma and Fear}

Many of the participants felt that stigma was not an issue when asked directly about it. However through further probing, it emerged that stigma was only a non-issue for them, due to the fact that most of them had not disclosed outside of their family circle. For those who have disclosed about their child's status, stigma and fear are very real challenges that they face on a regular basis.

One foster carer explained her decision to not disclose her child's status as follows:

...You start telling them that this child is HIV positive; they won't even want to sit next to her. You know that there are some people like that. They won't even want to drink from the same cup as her...so that is why I decided I can't tell my community, I can't tell the church people, it is going to be up to__ when she is big, who she wants to tell, or who she wants not to tell. 39-year-old foster mother

Two men who are cross population group foster fathers explained their experiences:

I'm still finding that even your upper class White community still don't understand. They still don't understand it - 40-year-old foster father

The ignorance is the biggest problem we've got. 44-year-old foster father

Many of the foster carers described their disbelief that people who they believe should be educated about HIV, still appear to be so ignorant, as evidenced by the following quote:

...In my road, there is teachers staying, there is policemen staying, and I always, I don't know, but I always thought that they is the people that will actually know what it is and really accept... But then its the people that is not even educated that accept _.. And they (the educated) are the people that should know better. - 58-year-old foster mother

Another foster mother echoed this sentiment:

You know, we've lost a lot of friends that used to come here. I know one couple definitely because I asked outright... 'Is it him? Because if it is, he's not going anywhere.' And the wife and the two little kids never even answered me, they just avoided me... it is more a case of fear than nasty people. - 48-year-old foster mother

Of the six cross population group foster placements, only one set of the participants reported experiencing stigma based on their ethnicity being different to that of their child, 
as evidenced through the following accounts:

Strangely enough the stigma we are getting is predominantly from the older Afrikaans women 40 -year-old foster father

And I have found it with African men. Twice I was at [shop] and she was asking for stuff and I kept saying no, no, no and eventually I stopped the trolley and said 'would you stop asking me for stuff because really, it's not going to happen. You've got all the stuff you're asking for at home.' And this black family stopped and the man said to me 'how dare you speak to her in that way, you don't deserve this child.' And I just turned to him and I said 'mind your own business' and he said 'she is my business, she's from my culture'. 44-year-old foster father

As these quotes suggest, it became clear through the course of the interviews that stigma is wide spread and not limited to the uneducated.

\section{Foster Carers Own Mental and Physical Health}

Most of the foster carers reported struggles with their own health, which adds considerably to the load that they carry, as evidenced by the following two quotes:

I'm like a doctor in my own house. I have to sort out my husband, he has epilepsy, I have to take my medication for high blood pressure, and I've got arthritis. I'm my husband's doctor, I'm my own doctor, I'm the kids' doctor. - 43-year-old foster mother

I got also diabetic....and I don't want to upset me or anything like that, otherwise I am going to get a stroke and die... I just take it cool. - 52-year-old foster mother

One foster carer claimed that occasionally foster carer's would miss their own medical appointment in order to take their foster child to appointments, as explained in this quote:

My grandmother used to, when it's _ appointment, maybe it's her (the grandmother's) appointment at the club for hypertension on the same day as appointment. Then she had to sacrifice for her treatment and come here for __. - 21-year-old female extended family member

A number of the older foster carers, particularly grandparents who are caring for their grandchildren, reported an added burden of dealing with their child's death and the reality that for many of them, at least one of their other children is also positive. This is evidenced through the following quote:

So there at home, I have nobody there, only my granddaughter...my daughter, my other daughter, she also got HIV. (Breaks down and cries) - 56 year old grandmother

It was clear that the older foster carers in particular found the stress of their own medical conditions and the emotional stress of looking after their foster child to be quite overwhelming at times.

\section{Managing the Foster Child's Medication}

The majority of the foster carers expressed a desire for their child to take responsibility for their own medication and many had made attempts to put systems in place to help their children to remember to take their tablets. One such attempt is described in the following quote:

My daughter, she did buy her a cell phone, but by the time the house burnt, then it burnt. But then she did have another one, lost. So now she don't have it. Because we did have it so that at 6 o'clock, the alarm can go and she must know to take her pills. - 52-year-old foster aunt

In most instances where foster carers had attempted to give their foster children responsibility for their medication (with age appropriate children), they had not been successful.

The majority of the foster carers reported that if they did not take charge of their child's medication, it would often be forgotten. This was illustrated through the following quote:

She is growing and getting a bit cheeky. Joh! She say 'ma, I'm going to eat the tablets, I'm going to eat the tablets', but she doesn't. And I say 'no, you mustn't do this, you saw your mother, she was so sick because she didn't drink the tablet, she did throw the tablet behind the bed. So you must drink your tablet.' Then she says 'ok ma, yes' and she drink the tablet. - 56-year-old grandmother

A 21-year-old extended foster family member echoed the sentiment:

She was taking her medication but she didn't like it and we had to beg her, you know, you have to understand, this is the rest of your life, don't choose to dodge it. When time for treatment, she refuses it all. And we thought she had a psychological problem, because she got so cheeky when it came to treatment and we have to beg and shout 'take your tablets' and if she doesn't want, she doesn't want.

It seemed that for many of the foster carers the struggle lay with the fact that they understood the importance of their foster children receiving their medication on time, and felt a responsibility to ensure that the medication was taken, despite their desire for their foster children to take responsibility for it themselves.

\section{The Foster Child's Emotional Pain}


In most of the circumstances it was clear that the child had been through significant emotional trauma. For many this involved the loss of a parent and many had been moved through children's homes or foster homes until eventually reaching the family where they are now.

Many of the foster carers felt a responsibility to help the children to deal with their pain, as evidenced in the quote below from a foster mother who took in three siblings, one of whom is HIV positive:

There was that time, especially for the bigger one, because she was the one who saw everything because the mother by that time was sick. She was the only one who was taking care of the mother and all that stuff. The only child that was not right is that big one. But because I talk, talk; talk with her, bit by bit, she became right, right, right. - 39-year-old foster mother

In one circumstance the teenage foster child had experienced the loss of her mother, and shortly after moving in with her grandmother, their house burnt down, killing her six-year-old brother. The foster carer was then dealing with her own grief about these circumstances and also trying to manage her granddaughter's grief. This was a huge burden for her, as expressed in the following quote:

We worry about her so much, she has gone through such a lot... and you know what, doesn't talk. If I can tell you, she doesn't talk...so you know what, last time she got also shingles, so it shows that she is not coping. -52-year-old foster aunt

Due to multiple failures on the part of social services, one of the participant's reported that she was told that she was not eligible to foster her child (due to the fact that she is foreign) after the child had already been living with the family for two years. The resultant uncertainty that this evoked in the foster child had a devastating effect on the child and the family, ultimately leading to the breakdown of the placement.

She freaked out one night and just tore apart her bedroom, throwing things and was sitting there with scissors in her hand looking at me...she was totally out of it, totally out of herself, and was just sitting there, with just like this look... She just sort of became angrier and angrier and just total lack of respect for us, not willing to engage... Kept herself isolated from the family and kind of would only join in when she felt like it and you know any kind of discipline or rewards or punishments didn't really have much of an effect. 55-year-old foster mother

One of the other participants reported on the trauma that her foster child endured after being placed with the family. After having lost her own parents and then having lived in residential care for a number of years, the foster child was placed with this family and developed a very close bond with her foster mother. The foster mother then passed away too, in the presence of the child and the child had to move in with the foster mother's adult daughter.

And you know what was so bad about that, the worst thing. She died in front of that was so bad. We couldn't even talk to for a week and we could see that there is a problem, that she is so scared. She hides every time behind the door. I took her here (to the hospital) so they counseled her but she didn't want to talk, she just cried...the first few months (after) she passed away, it was very difficult. We couldn't even know what to do. But she said you must not take back to the organization, she has to stay here. If she (grandmother) dies, we must take__ to my aunty. We thought it would be difficult, and it was difficult because we never know what to do, but then we decided as a family that really, she has to move because there is no one here. My mum goes to work, my sisters go to school, and I also go to school. - 21-year-old female extended foster family member

Five of the foster carers interviewed had taken on siblings and in each of these instances, only one of the siblings was positive. Each of them reported the strain that this had placed on the positive sibling at various times in their developing understanding of their HIV status, as evidenced in the following quote:

It's like she is no different. It's not a big thing to us. It's like she's got um, flu, and stuff like that. We all involving her, go and have your tablets and all that stuff. The time is 7 o clock now, go and have your tablets 39-year-old foster mother

When asked if the child doesn't have any problem with taking her tablets, she responded:

No. But there was a time when she did give me a hard time. 'No mom, I don't want to eat my tablets. It's like it's only me who is sick in this house and all that stuff. I'm sick and tired of the tablets.' - 39 year old foster mother

It would seem that if too many family members are involved in the process of encouraging the HIV positive child to take their medication, it can serve to further highlight the difference between that child and the rest of the family, and thereby potentially serve as a hindrance, rather than an encouragement.

\section{Discussion}

Foster carers of HIV positive children in South Africa face tremendous challenges and as a result, have significant needs related to providing care to their children living with HIV. The main challenges include the initial adjustment period, dealing with the child's HIV positive status, interactions with biological parents, finances, dual diagnoses, stigma and fear, their own mental and physical health, managing their foster child's medication and dealing with their foster child's 
emotional pain.

The finding that the initial adjustment to a foster care placement presents challenge to foster carers is consistent with the study by Simms, Dubowittz. and Szilagyi (2000), that found that a myriad of adjustment issues should be expected from children entering foster care. The strain of finances, dual diagnoses, stigma and fear, their own mental and physical health, managing their foster child's medication and dealing with the foster child's emotional pain are consistent with findings from the research conducted by Thomas and Mabusela (1991), Kiggundu and Oldewage-Theron (2009), and Kuo and Operario (2010) who found similar challenges to those identified in this study but considered them as a pile-up of caregiving challenges that included: economic challenges; challenges related to children's needs; and physical and mental health challenges (Buehler, Cox \& Cuddeback, 2003) This finding is consistent with the notion of 'pile up' in family stress theory that posits that families (including foster families) usually face multiple stressors, the combination of which can stretch the family's capacity to cope (McCubbin \& Patterson (1983).

The findings that many of the foster carers reported not having experienced stigma could be due to the fact that they are too afraid to disclose their foster child's status. This finding is consistent with a study conducted by Ogunmefun, et al. (2011), where foster carers were found to protect themselves and their foster child from stigma by choosing not to disclose. Unfortunately, by choosing to not disclose, they are potentially protecting themselves from stigma, but also potentially jeopardising their ability to access support that might be available to them if their foster child's HIV positive status was known (particularly at an organizational and schooling level).

Another finding was that foster carers perceive their role as that of providing love and a sense of belonging, discipline and boundaries, providing medical support, educating the child about their history and about HIV and the education of others about HIV. The finding that providing love and a sense of belonging was key for foster carers links to findings of studies by Blythe, Halcomb, Wilkes and Jackson (2012) and Warde (2008) who also found that foster carers saw emotional engagement as being a very important part of their role. These findings differ however to other research that has been carried out in the rural context of South Africa (Kuo \& Operario, 2010; Hearle \& Ruwanpura, 2009) where it was found that the day to day financial and material challenges as well as the challenging behavior of foster children made it difficult for foster carers to prioritise or feel passionate about providing love for these children in their care. This finding is however consistent with the basic assumption of systems theory that the family is a social institution that is interconnected and interdependent in which the whole is greater than the sum of its parts (Greene \& Ephross, 1991) and linked to the understanding of foster family dynamics (Greene \& Ephross, 1991).

A study by Hearle and Ruwanpura (2009) found that foster carers found that it was virtually impossible to enforce any form of discipline or boundaries with their foster children and as a result, many had given up. This is in contrast to the findings of this study, where the foster carers were realistic about the challenges of enforcing discipline and boundaries, but most still seemed to prioritise it as an important part of their role. It seemed that this aspect of discipline was most difficult for grandmothers, who struggled with their own feelings about their grandchild's loss and status and as a result saw discipline as adding to the child's difficulties.

\section{Conclusions}

The challenges facing foster carers of HIV positive children in South Africa are extensive and multifaceted. Foster carers of HIV positive children struggle to understand their foster child's adjustment during the period following initial placement especially for children who either came from residential facilities or who had just suffered the loss of a primary care giver. Foster carers should be provided with appropriate support mechanisms to adequately deal with the initial adjustment period. Foster carers found it very challenging to deal with situations where the foster child's HIV positive status was only known to them after placement in their care. For many this meant dealing with their own heartache, fears and concerns for the future, while remaining strong for their foster child. It is concluded that despite the fear and uncertainty that many foster carers experienced as a result of their foster child's HIV status, the revelation of their child's status often resulted in a renewed sense of purpose in their care of their foster child.

Interaction with the biological parents of a foster child is often traumatic for foster carers and presents its own set of challenges, as is dealing with multiple diagnoses in the same child. These challenges were far more stressful and time consuming to manage than dealing with the reality of the HIV status of the child. HIV-related sigma is reportedly not a major challenge as most foster carers do not disclose the HIV status of their foster child outside of their family circle. Notwithstanding this, foster carers should be encouraged to disclose the HIV status of children in their care and provided with appropriate social and emotional support mechanisms to enable disclosure outside the family given the documented benefits of disclosure.

Most of the foster carers reportedly struggled with their own psychological health, it is concluded that creating a space in which foster carers could speak about the challenges that they face would prepare them psychologically, to deal with the realities of fostering a child living with HIV. This highlights the need for additional emotional support for foster carers and the importance of creating forums in which they can be given the opportunity to talk through their struggles and concerns and when appropriate, receive appropriate training. Further research with HIV positive 
foster children might be useful to understand their perspective about the challenges and needs of their foster parents.

\section{Acknowledgements}

The authors would like to express their sincere gratitude and appreciation to the foster parents for their courage and passion with which they provided insights into the challenges related to providing foster care to an HIV positive child in South Africa. We thank you ever so much!

\section{REFERENCES}

Babbie, E., \& Mouton, J. (2007). The Practice of Social Research. Cape Town: Oxford University Press.

Blythe, S.L., Halcomb, E.J., Wilkes, L., \& Jackson, D. (2012). Perceptions of long-term female foster carers: 'I'm not a carer, I'm a mother.' British Journal of Social Work online publication, 1-17.

Boyer, N.C., \& Poindexter, C.C. (2005). Barriers to permanency planning for older HIV-affected caregivers. Journal of Gerontological Social Work, 44(3/4), 59-74.

De Vos, A.S., Strydom, H., Fouche, C.B., \& Delport, C.S.L. (2005). Research at grass roots: For the social sciences and human service professions $\left(3^{\text {rd }} \mathrm{ed}\right)$. Pretoria: Van Schaik Publishers.

Greene, R.R., \& Ephross, P.H. (1991). Human Behaviour Theory and Social Work Practice. New York: Aldine De Gruyter.

Hearle, C., \& Ruwanpura, K.N. (2009). Contentious Care: Foster Care Grants and the Caregiver-Orphan Relationship in KwaZulu-Natal Province, South Africa. Oxford Development Studies 37(4): 423-436

Jones, S.A., Sherman, G.G., \& Varga, C.A. (2005). Exploring socio-economic conditions and poor follow up rates of HIV-exposed infants in Johannesburg, South Africa. AIDS Care, 17(4), 466-470.

Kiggundu, E., \& Oldewage-Theron, W. (2009). Coping: A challenge for guardians of children orphaned by HIV/AIDS in a South African township. Development Southern Africa, 26(3),
383-397

Kuo, C., \& Operario, D. (2010). Caring for AIDS-orphaned children: an exploratory study of challenges faced by carers in KwaZulu-Natal, South Africa. Vulnerable Children and Youth Studies, 5(4), 344-352.

Maluccio, A.N. (2003). Processes and outcomes in family foster care: A selective North-American review. International Journal of Child and Family Welfare, 6(4), 133-140.

McCubbin, M.A. (1993). Family stress theory and the development of nursing knowledge about family adaptation. In S.L. Feetham, S.B. Meister, J.M. Bell, \& C.L. Gillis (Eds.) The Nursing Family (pp. 46-58). New Bury Park; Sage Publications.

Murray, L., Tarren-Sweeney, M., \& France, K. (2010). Foster carer support and training in the context of a high burden of care. Child and Family Social Work, 16, 149-158.

Nyasani, E., Sterberg, E., \& Smith, H. (2010) Fostering children affected by AIDS in Richards Bay, South Africa: a qualitative study of grandparents' experiences. African Journal of AIDS Research. 8(2), 181-192, DOI: 10.2989/AJAR.2009.8.2.6.858

Ogunmefun, C., Gilbert, L., \& Schatz, E. (2011). Older Female Caregivers and HIV/AIDS-Related Secondary Stigma in Rural South Africa. Journal of Cross Cultural Gerontology, 26, 85-102.

Rajcoomar, U. (2005). Has the impact of HIV and AIDS affected the lives of rural 'gogos'? http://www.oxfamireland.org/pdfs/longt erm/johap_casestudy04.pdf (accessed 22 March 2012).

Rymph, C.E. (2012). From "economic want" to "family pathology": Foster family care. The new deal, and the emergence of a public child welfare system. The Journal of Policy History, 24 (1), 7-25.

Simms, M.D., Dubowitz, H., \& Szilagyi, M.A. (2000). Health care needs of children in the foster care system. Pediatrics, 106, 909-918.

Strijker, J., Knorth, E.J., \& Knot-Dickscheit, J. (2008). Placement history of foster children: A study of placement history and outcomes in long-term family foster care. Child Welfare, 87(5), $107-124$

Thomas, A., \& Mabusela, S. (1991). Foster care in Soweto, South Africa: Under assault from a politically hostile environment. Child Welfare, $\operatorname{LXX}(2), 121$ - 130.

Townsend, L., \& Dawes, A. (2004). Willingness to care for children orphaned by HIV/AIDS: A study of foster and adoptive parents. African Journal of AIDS research, 3(1), 69-80. 